\section{Cor \& sentimento: \\ uma investigação \\ sobre imagens de \\ violência na \\ Internet}

RESUMO

\section{Graciela Ormezzano}

Doutoranda em Educação

Faculdade Educação - Progr.. Pós-Grad. Educação / PUCRS
QUAIS AS IMAGENS que representam a violência na Internet? Há uma violência real ou simbólica nesta estética virtual? Os símbolos da arte eletrônica contemporânea permitirão compreender o imaginário dos internautas? Esta arte efêmera será, no futuro, patrimônio histórico-cultural da humanidade ou ela está fadada ao desaparecimento?

Morin diz:

“...só se pode preparar um futuro salvando um passado, e estamos num século em que múltiplas e potentes forças de desintegração cultural atuam." (1997, p. 17)

As obras de arte permitiram, até o momento, documentar a história da humanidade, embora não seja esta sua principal motivação de existência. A arte mostra o imaginário de nosso tempo, superando o passado e preparando-se para o futuro. A ênfase da sociedade atual está na comunicação das informações, no banal, na técnica eletrônica, nos multimídia, na desmaterialização do mundo pela substituição simbólica. "A arte virtualiza as virtualizações, tentando saídas de situações limitadas a um aqui e agora físico e/ou simbólico" (Lemos, 1997, p. 24).

Embora as imagens da Internet possam escapar à representação clássica dos padrões tradicionais ocidentais, o paradoxo está na sua semelhança com o período renascentista, ao criar uma concepção anaturalista do espaço que possui sua correspondência na exclusão de elementos temporais. Este período crítico manifestou sua subversão ao olhar medieval, não respeitando a 
ordem cronológica ou a lógica temporal dos acontecimentos e das figuras (Bozal, 1996). A representação caótica da relação espaçotemporal emerge hoje, provocando a crise estética, utilizando um conjunto crescente de técnicas fotográficas e televisivas e o modelo digital do real que reformula as imagens, não como um meio de representar o Universo, mas como a sua digitalização.

A imagem é simbólica. As imagens digitais desnaturalizam o objeto, perdendo o vínculo com a natureza. Sendo elas puramente imaginárias poderão tornar-se operacionais através da linguagem cibernética que não mais representa a realidade, simula-a (Lemos, 1997). A arte eletrônica constitui uma expressão simbólica que joga com movimentos, sons, formas e cores, quebrando as fronteiras entre o produtor, o objeto artístico e o espectador, sendo a interatividade sua principal característica.

As formas imagísticas têm se transformado, ao longo dos séculos, mas o simbolismo das cores ultrapassa os limites do temporal. Portal escreveu, no século passado, o tratado mais amplo existente sobre a cromática e sua simbologia, baseado nas tradições milenares -chinesa, hindú, grecoromana, cristã e outras. Este autor considerou três linguagens para seu estudo: a linguagem divina, reveladora da existência de Deus; a sagrada, que regula o simbolismo na arte e nos rituais; e a profana, expressão material dos símbolos, com as diversas significações desta ciência (Portal, 1996).

Ao olhar as imagens, consideramos tanto a forma quanto as cores. A extensão deste trabalho não nos permitiu fazer um aprofundamento em ambos os conceitos. Optamos pelo simbolismo cromático, em razão de sua atemporalidade e por ser ela mais vinculada ao visceral do que ao racional. A cor, incluindo o preto e o branco, está intimamente ligada aos sentidos. Sentir implica vivenciar-nos a nós mesmos em relação a algo (Ulich, 1985). Este algo pode ser qualquer coisa, neste caso, as imagens de violência na Internet. Os sentimentos e as cores se amalgamam no significado, dado pelo grupo entrevistado, às imagens pesquisadas.

Cor, metáfora do sentir. "O colorido está para a cor como a pintura para o visível (...) Pela cor a pintura imita a natureza..." (Kossovitch, 1993, p. 204). A cor relaciona-se mais com o sensível (corpo), enquanto a forma ao inteligível (espírito), mas uma não pode existir sem a outra.

Por meio deste estudo, compreendemos alguns componentes do percurso gerativo de sentido, produzido e interpretado pelas imagens de violência na Internet. Escolhemos, para realização desta investigação qualitativa, uma metodologia de cunho semiótico, a qual nos auxiliou na interpretação dessas imagens.

Esta investigação foi desenvolvida nas seguintes etapas: construção do corpus teórico, que acompanhou o desenvolvimento de todo o estudo; busca das imagens de violência, navegando a esmo na Internet, entrando em diversos endereços eletrônicos; leitura subjetiva das imagens impressas por um grupo multidisciplinar de pesquisadoras/pesquisadas, da Pontifícia Universidade Católica do Rio Grande do Sul ${ }^{1}$; compreensão e interpretação das informações e comunicação dos achados.

Foram selecionadas sete imagens, número que consideramos adequado, tratando-se de uma pesquisa qualitativa. As nove mulheres, integrantes da equipe, observaram e leram as imagens de maneira subjetiva sem estipular, a priori, qualquer modo de leitura, mas lhes foi solicitado para responder a este olhar intuitivo, com uma palavra, frase ou seqüência de termos.

No ato de olhar, significamos. A imagem é fonte de significação. O símbolo é recondução do sensível ao significado (Durand, 1995). Esta metodologia de pesquisa está embasada na semiótica, desenvolvida por Moragas Spa, que tenta descobrir a significação da imagem e a provável atitude dos seus leitores. Cabe destacar que, para este autor, a inflação de violência, apresentada pela mídia, constitui uma solução de contraponto para promover valores publici- 
tários (Moragas Spa, 1980). A distância entre o público e o drama contrasta com a relação de euforia que a publicidade lhe propõe, participando de forma simbólica do grande crescimento do consumo, aceitando a proposta de um modelo ideal de imagem pessoal e levando-o, subtilmente, a consumir , no caso da Internet, pelo mínimo, impulsos telefônicos. Ao mesmo tempo, a informação de fatos dramáticos exerce um papel de imunização a respeito da tomada de consciência dos problemas reais da sociedade e da pessoa.

À medida que fomos avançando na interpretação, relacionamos a violência ao simbolismo universal das cores e à linguagem subjetiva dos sentimentos. Consideramos que, olhando as imagens violentas, as participantes do estudo reagiriam de modos distintos. As atitudes emocionais básicas das pessoas afetadas pela violência se reduzem a processos educacionais dentro da família e a outras instâncias de socialização (Ulich, 1985). Buscamos identificar as proximidades semânticas entre as falas, referidas à mesma família de significação, não pretendendo com isto estender-nos a uma generalização. A repetição nas sete imagens não significa o universo cultural da violência na Internet. Isto poderia ser diferente com maior quantidade de imagens, com outras imagens ou com leitores diferentes. Pretendemos nos aproximar de uma interpretação destas imagens obtidas, considerando, também, que em todas elas se destacam, de forma absoluta, unicamente, tres cores, o branco, o vermelho e o preto. Como as falas se referiam, em sua maioria, a sentimentos, procuramos as ligações entre ambos: cor e sentimento.

Essa perspectiva da união sujeito-objeto, pesquisador-pesquisado traz uma alteração metodológica e epistemológica em qual a mentalidade "científica" não passa de uma ilusão da educação universitária, obstaculizando a simbolização e o poder da imagem, em proveito do lucro material. O conceito de símbolo é "o encontro necessário entre a identidade do simbolizante e do simbolizado, transcendendo os limites locais situados no que a física moderna chama de "não-separatividade" (Durand, 1995).

A física newtoniana reconhece sete cores constitutivas da luz do sol, decomposta pelo prisma: roxo, azul-índigo, azul, verde, amarelo, laranja e vermelho. No final do Século XVIII, Goethe se opõe a esta teoria, após várias experiências com prismas e lentes. Ele diz que a claridade não pode ser composta de cores, pois que se a luz está revestida de uma cor é mais escura do que a luz incolor em si (Goethe, 1993). Atualmente, pensa-se que o cromatismo focaliza a energia sobre as superfícies e a instala dentro de seus limites; no interior destas áreas, a intensidade luminosa se converte em cores, tons e valores, produzindo uma estreita ligação entre a cor e a identidade da zona mencionada (Fontanille, 1998).

Para o estudo do simbolismo das cores, são considerados dois princípios que dão origem a todas as cores, a luz e as trevas. A luz, simbolizada pelo branco e, as trevas, pelo preto. A luz não existe sem o fogo, expresso no vermelho, partindo desta base se admitem duas cores primigênias: o vermelho e o branco (Portal, 1996).

Há uma dicotomia nas falas das entrevistadas, que podemos sintetizar como a eterna luta entre o bem e o mal, representada pelo branco e o preto, emergindo como um dos aspectos mais marcantes da pesquisa. O bem existe oposto ao mal, a verdade ao erro, a sabedoria à ignorância e as trevas se opõem à luz, como o preto ao branco. Onde a luz termina, aparece a sombra. Ao terminarem os raios da sabedora divina, começa o erro. O ser humano pode optar, livremente, por um ou outro mundo, e no seu espírito lutam, permanentemente, estas forças opostas. A sombra é uma projeção da mente consciente da pessoa. Contém os aspectos ocultos, reprimidos e desfavoráveis da personalidade. Na luta para alcançar a consciência, este conflito é representado pela disputa entre o herói arquetípico e os poderes do mal (Henderson, 1977). O arquétipo é um produto do inconsciente co- 
letivo, existente em nosso íntimo sem limites no espaço ou no tempo. Constitui um retrato das atitudes do ser humano. Os arquétipos são dinâmicos, entram na esfera pessoal da psique, no inconsciente pessoal e se expressam por meio de imagens que realizam uma ponte entre a consciência e o inconsciente (Hauser, 1994).

O branco reflete os raios da luz, os profetas de Israel chamam a sabedoria divina pureza da luz eterna. Yehovah aparece vestido de branco. No Gênese, nas tradições do Egito e Índia, na Grécia Clássica, nas cosmogonias de quase todos os povos, a luz é símbolo do divino e, o branco, a cor consagrada ao Ser Superior. Mas o branco foi, também, cor mortuária. No Apocalipse, a vestidura branca era um prêmio à vitória (Portal, 1996). Uma das entrevistadas menciona que o branco não lhe transmite paz, nestas imagens, mas o "mascaramento". Ameaças sem rosto nos fazem sentir a impotência de não saber a quem encarar, ou aonde está o perigo.

A ansiedade é um sentimento muito freqüente no mundo em que vivemos, às vezes, sentimo-nos indefesos para enfrentar as ameaças de agressores invisíveis como: os fluxos da economia, a devastação das florestas, os buracos na camada de ozônio, os hackers, o governo...

O preto designa a matéria. Ela, em si própria, não possui conotação maléfica. A matéria é a motivação do mal, encontrado na alma dos seres humanos. Quando a pessoa está espiritualizada, desprende-se do seu aspecto carnal e atravessa as portas da morte, entrando no que o pintor De Chirico enuncia como um "vazio metafísico" (Jaffe, 1977; Portal, 1996). O caráter simbólico da luz e da escuridão é traduzido pelas propriedades inerentes aos objetos; a morte, por exemplo, pode aparecer como uma figura preta ou a melancolia com um rosto preto (Arnheim, 1980).

As divindades invocadas nos rituais como imagens da morte eram pretas: no Egito, a Isis tenebrosa e a Athor; na Grécia, a Vênus Melanis e a Ceres vestida de preto; no Cristianismo, temos a Virgem negra. O preto simboliza a morte, o luto pela destruição do corpo material. Símbolo do mal e da mentira é a negação de todas as cores e do que elas representam (Portal, 1996). Na percepção, a escuridão não aparece como simples ausência de luz, mas como um contraprincípio ativo, o que implica dinamismo (Arnheim, 1980).

As deusas negras se relacionam com a água. Na China, o elemento água também é preto. Há quatro cores atribuídas universalmente aos quatro elementos: ao fogo, o vermelho; ao ar, o azul; o verde para simbolizar a água e, o preto, para simbolizar a terra, elemento do corpo, da natureza animal, do trabalho, aspectos mencionados pelas participantes da pesquisa. Esta cor neutra ou valor pode ser descrita como um modo de evolução espiritual, relacionado ao mundo dos sentidos, ao mundo da aparência material, dos impulsos irresistíveis provenientes do físico, psíquico ou moral (Portal, 1996).

O estado de depressão produz vazio, tristeza, solidão. Estes sentimentos seguem a alguma ferida ou perda. O vazio e o isolamento são mais profundos quando a pessoa que sofre tenta limitá-los. Pode-se perder a razão ou comportar-se como se a tivesse perdido para aliviar a dor. Quando se teve uma perda importante, há pessoas que não conseguem resolver o sofrimento e tendem a utilizar mecanismos defensivos, na maioria dos casos, de negação da realidade. Talvez, a perda mais difícil de aceitar é a que nos obriga a ver nossas próprias dificuldades e deficiências (Viscott, 1978).

O vermelho é símbolo do amor regenerador, de almas piedosas. Na Antigüidade representava as divindades do amor, vestia os pontífices e a realeza. Os maus, também, levam vestes púrpuras e carmim pois, o Diabo é vermelho. Esta cor deixa de ser o símbolo do fogo e do amor e representará, mais tarde, o sangue derramado nos campos de batalha e pelo algoz. Significa, ao mesmo tempo, amor, egoísmo, ódio e todas as paixões do ser degradado (Portal, 1996). 
Ao estar relacionado ao elemento fogo, o vermelho representa, também, a vontade, a moral, o desejo. A tarefa que implica este elemento é a transformação, pois dela depende que seu caminho ascenda ao encontro da perfeição ou descenda aos reinos inferiores, em outras palavras, a diferenciação entre o bem e o mal (Adler, 1981).

A raiva traduz a frustração, a fúria, a irritação, o ódio. A tristeza é um sentir permanente, alimentado pelo ódio que pode enfermar a quem a padece, no desespero por conter o ódio de si mesmo. A raiva se descarrega, sem alvo definido, sem entrar, necessariamente, em contato com o real, com a ferida que a originara. Pode até ser saudável liberar nossos sentimentos, acumulados de dor, por meio de um pouco de raiva; mas quando as pessoas expressam na ação suas necessidades de vingança, querem também destruir. Às vezes, as fantasias chegam a ser tão violentas que criam uma auto-imagem monstruosa (Viscott, 1978).

Durante a leitura imagística, surgiram palavras que traduziam sentimentos. Entre os mais mencionados, destacou-se a ansiedade produzida pelo conflito entre o bem e o mal e, ao mesmo tempo, pelo temor de sermos agredidas pelos inimigos anônimos, próprios de uma cibercultura. Navegantes desconhecidos invadem para espionar ou destruir as informações, armazenadas nos computadores pessoais ou nos das organizações, perseguindo emoções vinculadas ao desejo de poder e/ou de fins lucrativos completamente insensíveis às conseqüências que isto possa acarretar à vida de uma pessoa. Nossa privacidade está exposta aos amorais, nossos dados de identificação à infinidade de vendedores de quaisquer produtos, as crianças à pornografia...

Seria interessante poder identificar a própria violência nas imagens trabalhadas e perguntar-nos, aonde estamos nós? Pela compreensão destas imagens, refletimos sobre nossa interioridade, o mundo, a emergência do fenômeno bem-mal. Esta dicotomia mostra a fatalidade de um destino a ser vivido, entre o céu e o inferno, vida e morte, verdadeiro e falso, fantasia e entendimento.

A função simbólica da máscara que aparece entre as imagens trabalhadas é a do disfarce. A Internet é uma grande mascarada na qual a expressão dos sujeitos desaparece ante o significado do simbolizado ou do simulado. A nova violência pode estar oculta atrás da máscara que tentamos descobrir. Uma descoberta complexa, um desafio, um jogo intelectual, uma possibilidade emocional, uma não-certeza...

Talvez, os leitores considerem esses resultados muito ligados ao misticismo ou ao esoterismo e afastados do que, habitualmente, considera-se pesquisa "científica". Neste caso, caberia lembrar que as artes surgem da magia, do mito, das religiões. $\mathrm{O}$ ser humano pré-histórico desenhava os animais nas paredes das cavernas, acreditando que este ritual auxiliá-lo-ia no momento da caça. Qual o significado dos maravilhosos templos e túmulos egipcios, senão uma arte surgida das crenças na continuidade da vida após a morte? A partir do Cristianismo, a temática religiosa constrói a imagem divina, século após século. Somente mais tarde, a nobreza - seres humanos mortais será a temática nas telas dos artistas da Modernidade. Mesmo, hoje, no resgate da espiritualidade ou simbolizando forças demoníacas, a nossa cultura está invadida de imagens nas quais interagem a religião e a arte -

\section{Nota}

1 Pesquisa realizada sob a orientação da Prof ${ }^{a}$ Dra. Valdemarina Bidone de Souza do Programa de Pós-Graduação em Educação, da Pontifícia Universidade Católica do Rio Grande do Sul.

\section{Referências}

ADLER, Oscar. La astrología como ciencia oculta. Buenos Aires: Kier, 1981. 
ARNHEIM, Rudolf. Arte e percepção visual: uma psicologia da visĩa criadora. São Paulo: Pioneira; USP, 1980.

BOZAL, Valeriano, e outros. História Geral da Arte: Escultura II. Espanha: del Prado, 1996.

DURAND, Gilbert. A fé do sapateiro. Brasilia: UnB, 1995.

FONTANILLE, Jacques. "Reflects, transparences et images: les figures du visible". In OLIVERRA, Ana C.; FECHINE, Yvana (eds.), Semiótica da Arte: Teorizações, análises e ensino. São Paulo: Hacker; CPS, 1998. p. 21-43.

GOETHE, Johann W. Doutrina das Cores. São Paulo: Nova Alexandria, 1993.

HAUSER, Ana. A linguagem plástica do inconsciente. São Paulo: Ática, 1994.

HENDERSON, Joseph. "Os mitos antigos e o homem moderno". In: JUNG, Carl G. (org.), O homem e seus símbolos. Rio de Janeiro: Nova Fronteira, 1977, p. 104-157.

JAFFE, Aniela. "O simbolismo nas artes plásticas". In JUNG, Carl G. (org.), O homem e seus símbolos. Rio de Janeiro: Nova Fronteira, 1977, p. 230-271.

KOSSOVITCH, Leon. "A emancipação da cor". In NOVAES, Adauto (org.), 0 othar. São Paulo: Companhia das Letras, 1993, p. 183-217.

LEMOS, André. "Arte, Eletrônica e Cibercultura". Revista FAMECOS, Porto Alegre, n. 6, p. 21-31, junho 1997.

MORAGAS SPA, Miquel de. Semiótica y Comunicación de Masas. Barcelona: Península, 1980.

MORIN, Edgar. "Imaginários da educação: por uma reforma da Universidade e do Pensamento". Revista FAMECOS, Porto Alegre, n. 6, p. 17-20, junho 1997.

PORTAL, Frédéric. El simbolismo de los colores: en la Antioizedad, la Edad Media y los tiempos modernos. Barcelona: Sophia Perennis, 1996.

ULICH, Dieter. El sentimiento. Introducción a la psicología de la emoción. Barcelona: Herder, 1985.

VISCOTT, David. El lenguaje de los sentimientos. Buenos Aires: Emecé, 1978. 